\title{
Endoscopic endonasal surgery of anterior cerebral fossa
}

\author{
K.Bouaita, Shabay.Z, N.Ioualalen \\ Department Of Neurosurgery, Hospital Ali Ait Idir, University Of Algeries, Algeria
}

\begin{abstract}
The objective of this study is to present our experience in endoscopic surgery of lesions in the anterior skull base, to describe the transcribrifom endoscopic technique and show its indications and contraindications.

We present a series of 73 patients operated at Ali AitIdir Hospital by extended endoscopic approach (trans cribriform endoscopic approach) including: 16 fronto-ethmoidal meningo-encephalocoele, 04 esthesioneuroblastoma, 04 ethmoidal adenocarcinomas with intracranial extension, 45 dural defects at the cribriform plate of ethmoidal bone and 04 olfactory meningiomas. 32 females and 41 males with a mean age of 35,5 years. Anosmia was the major symptom in olfactory meningiomas.

For the cerebrospinal fluid leakage due to dural defects, the most frequent clinical symptom was rhinorrea, associated with meningitis in 37 patients. The most frequent dural defect site was the cribriform plate of the ethmoid bone in 42 patients. Other clinical signs were nasal obstruction, exophtalmia, respiratory distress and epistaxis. All the patients were operated by a trans cribriform trans ethmoidal endonasal endoscopic approach, with good post operative outcomes.Eight patients were sent to radiotherapy. Long term follow up revealed recurrence of rhinorrhea in 04 patients operated for a dural defect.
\end{abstract}

Keywords: - : cribriform plate of the ethmoid bone, meningoencephalocoele,rhinorrhea;; trans-ethmoidal transcribriform endoscopic route, radiotherapy.

\section{Introduction}

Tumours of the anterior skull base are generally resected by a transcranio-facial or trans- anterior skull base approach, the latter more often involving brain retraction and is responsible for the risk of seizures.

The reconstruction of the cranial base is complex and difficult, leads to the risk of CSF fistula, meningitis and skin necrosis. The transsphenoidal approach of the anterior skull base was first proposed over a hundred years ago.Initially, these approaches were restricted to the pituitary fossa, but with the gradual development of technology coupled with deeper knowledge of the regional anatomy, transsphenoidal approach was extended to the sellar neighboring regions to include other entities in addition to sellar tumors. Of recent the endonasal endoscopic approach for tumors of the anterior cranial fossa has been reported(2-3-6-7-9-12-13). In the trans- ethmoidal endoscopic approach, thetrans - cribriform approach is the most rostral extension of the standard transsphenoidal approach which is from the front of the sphenoid planum to the posterior part of the frontal sinuses. The purpose of this research is to study: the indications of endoscopic surgery and their limits, the surgical technique and its particularity according to the tumors of the anterior skull base.

\section{Patients And Methodes}

We present a series of 77 patients operated on in Ali AitIdir hospital by extended endoscopic approaches (the endoscopic trans cribriform approach) between 2010-2014 including: 16 fronto-ethmoid meningo-encephalocoele, 04esthesioneuroblastoma, 04 ethmoidal adenocarcinomas with intracranial extension, 45 dural defects at the cribriform plate of ethmoidal bone and 05 olfactory meningiomas and 3 others(recurrence of meningioma of the orbital roof, nasopharyngeal fibroma and ethmoid orbital osteoma)

This is a retrospective study of 34 females, 43 males with an average age of 35.5 years. Anosmia is the major symptom for olfactory meningiomas with well controlled seizure attacks under antiepileptic treatment lasting for a few months.For dural defects the most common clinical symptom is rhinorrhea associated with meningitis in 37 patients. There is a notion of unilateral nasal obstruction in 15 patients. The most frequent location of the CSF fistula is the cribriform plate of the ethmoid bone in 42 patients.

Other clinical signs are nasal obstruction, proptosis, difficulty in breathing and epistaxis. All patients were operated by endoscopic endonasal trans ethmoidal cribriform approach, with good postoperative outcomes.

Besides for dural defects (we prefer the sagittal, coronal and frontal views ofbrain scan cut into thin slices to view the bone defect and check the anatomy of the lateral nasal wall); all patients underwent a CT scan and MRI before and after the surgery.

All patients were operated by endoscopic endonasal trans cribriform approach.

III. The surgical procedure 


\section{The Trans Cribriforme approach for anOlfactoryMeningioma}

This trans- ethmoidal trans - cribriform endoscopic approach, is the most rostral extension of the standard transsphenoidal approach, bounded in front by the frontal sinus, posteriorly by the sphenoidal planum laterally with the lamina papyracea and the medial wall of the orbit, the roof is the gyrus rectus and the orbitofrontal gyrus, which are easy to exhibit like olfactory nerves bilaterally.This is a difficult surgery that requires preoperative preparation of the patient with an anesthesia consultation, treatment of comorbidities such as high blood pressure and diabetes.

-a standard laboratory tests with fibrinogen levels.

-a preoperative antiepileptic treatment is needed to prevent and avoid epileptic seizures evenpostoperatively.

-preparation of reconstruction materials for the skull base after tumor resection or in the case of a CSF fistula (the synthetic dura mater, fibrin glue .......)

Patient under general anesthesia with tracheal intubation, cardiac monitoring, and oropharynx is filled with a packing in order to avoid the inhalation of blood. The patient is placed supine, with a raised trunk $20 \%$ at the end to reduce venous bleeding. The head is straight, slightly turned towards the surgeon and the neck on extension of $30^{\circ}$ to facilitate the exposure of theanterior sub frontalcranial compartments. The anterolateral thigh is prepared to take the fascia lata as duroplasty.

\section{Disinfection of nasal cavities:}

For disinfecting and decongesting nasal cavities, soaked cotton pads Betadine are placed along the floor of the nasal cavity and into the space between the nasal septum and middle turbinate, followed by disinfection of the periphery of the nose and the front, then is placed in long cotton impregnated with a vasoconstrictor ( chlor - chlorhexidine gluconate 5\%) between the middle turbinate and nasal septum .It is supposed to wait for a few minutes before starting the procedure. This procedure takes place in two phases: Naso - sinus and intracranial.

The Naso-Sinusal Phase:also known as the epidural exposure phase.

Under endoscopic view ( rigid endoscope $0^{\circ}, 18 \mathrm{~cm}$ length, diameter $04 \mathrm{~mm}$ ), the lower, middle and upper turbinates are identified, the endoscope is advanced into the choana, then to the middle and superior turbinates.

The middle turbinates are resected bilaterally at the base of the skull, after coagulation of their basic insertion by the monopolar coagulation; followed by resection of the mucosa of the nasal septum cartilage and the upper third of the resection of the septal attachment to the roof of the nasal cavity, thus creating a large cavity(Fig 2-3) .This maneuver can compromise olfaction but generally it is already compromised by the lesion.At this stage, the endoscope is placed in a nostril and the instruments are placed through the other nostril or both.Can we start with the incision of the uncinate process ( falx) by ascalpelparallel to the lamina papyracee to avoid entering into orbit and continue laterally and below to the ostiumof maxillary sinus(fig 4-5). The uncinate process is resected to its anterior attachment, thereby exposing the front wall of the ethmoidal bulla.Anterior ethmoid cells are open both sides, the basal lamella of the middle turbinate is resected to expose the posterior ethmoid cells that will be opened later for a complete ethmoidectomy .

The latter is followed by exposure of internal orbital walls. The nasofrontal or frontal recess is exposed in front with complete resection of aggernasi cells to allow broad exposure of the skull base(6-7). For achieving devascularization of the tumor, the anterior ethmoidal artery is identified and coagulated with bipolar at the junction of nasofrontal recess / ethmoid sinus roof and the posterior ethmoid artery which is located next to the junction of the sphenoid sinus and posterior ethmoid cells to be identified and coagulated(Fig 8).

After exposure of the cribriform lamina that appears infiltrated and invaded by the tumor, one begins the resection of the latter with the kerrisson and a hyperrapid strawberry punch bilaterally, drilling begins at the posterior part the fronto- ethmoid recess and continues towards the posterior sphenoid sinus in a rostral -caudal direction(Fig 9). The lateral extension of the drilling is limited between the fovea and ethmoidalis lamina papyracea. The mastoid Crista Galli is drilled to become thin eggshell, and then fractured and resected by a small gouge forceps. This step results in a single large cavity at the anterior part of the skull base. In the first case, there is a tumor extension to the posterior planum where the opening of the sphenoid sinus and resection of sphenoid planum.

Intracranial phase Starts after opening the dura on each side of the falx in the second case, but in the first case, the dura has already been invaded by the tumor, the latter is taken with the cribriform plate in the riddled kerrisson(Fig10). The dissection and resection of a lesion in this region follows certain principles using microsurgical instruments and a specific bipolar.

Tumor resection is in three parts: 
a- The tumor devascularization.

b- The reduction in tumor volume.

c- Dissection and resection of the tumor capsule.

d- The closure.

2-A: Tumor devascularization: Coagulation of anterior and posterior ethmoidal arteries helps to devascularise the tumor in addition to the careful coagulation of the dura before opening allowing additional devascularization; this represents the initial advantage of endoscopy.The anterior falx artery remains supplies residual tumor with some cortical vessels occurring in the anterior circulation of the circle of Willis. After devascularization of the tumor, one begins the second step which consists in:

2-b-reducing the tumor volume: Which consists of an intra- capsular excision done depending on the tumor consistency with a rigid endoscope $30^{\circ}, 18 \mathrm{~cm}$ in length, $04 \mathrm{~mm}$ in diameter, using the technique ultrasonic -surgical aspiration (type Sonystar) with a probe specific for endonasal approach for both sides to expose the free edge of the falx bilaterally, micro scissors and grasping forceps(Fig11).The tumor vessels originate fromthe anterior artery of the falx, they can be identified from either side of the free edge of the scythe.These vessels are coagulated and sectioned along the falx, the latter is incised to create a single intra dural cavity. To prevent herniation of the brain into the operative field, the anterior dura mater is left intact. Intra capsular piecemeal excision continues until leaving a thin tumor capsule, then begins the last step of dissecting the latter from the cerebral cortex and anterior parts of the circle of Willis.

2-c-Theextra capsular dissection: Is a difficult step which will be executed carefully; since the tumor capsule becomes thin and pliable enough after internal decompression allowing its retraction(Fig12). A soft retraction produces a voltage sufficient to allow an extra capsular dissection using a dissection spatula and small cotton, first at the inter hemispheric fissure and the anterior pole which corresponds to the inferiorsurface of the gyrus rectus along the posterior superior pole, the dissection of the superiorsurface must be done extremely carefully because segment A2 and the fronto- polar branch of the anterior cerebral artery drape the upper surface of the tumor.After resection of the tumor capsule, we proceed with checking the operative cavity in search of a residual tumor(Fig 13).Hemostasis is perfectly achieved, the cerebral cortex is protected by the layers of surgicel.

2-d-The closure :Atthe end of the procedure, the reconstruction of osteo- dural defect is done according to the size of the opening, with the goal of a sealed closure. The anterior floor of the base of the skull is closed in multilayers with fibrin glue and the ball of a urinary catheter.

After collection of the fascia lata at the anterolateral aspect of the thigh, the first layer of fascia latais placed intra- durally followed by the application of fibrin glue, a second layer of the fascia lata and then the bone of the middle turbinateand middle turbinate mucosa taken previously, followed by the fat and Surgicel, the whole thing is maintained by a urinary catheter balloon inflated with saline to $12 \mathrm{cc}$ for 5 days. We use the Valsalva manœuvre for searching an eventual CSF fistula.

\section{Results}

Postoperative period was uneventful, nasal packing and urinary catheter were removed on the fifth postoperative day.The hospital stay is 07 days, no CSF fistula or postoperative complications.

\section{Extent of resection: Table No.01}

\section{Discussion}

The tumor lesions of the anterior skull base floor will be handled by an extended endoscopic approach. The trans cribriform approach is bounded in front by the frontal sinus, posteriorly by the sphenoidal planum laterally with the lamina papyracea and the medial wall of the orbit, above is the gyrus rectus and the orbitofrontal gyrus that are easy to expose as olfactory nerves bilaterally.

The trans-ethmoidal endoscopic approach, trans-cribriform is performed either unilaterally or bilaterally depending on the injury. In general the unilateral approach is reserved for meningo-encephalocele, and the meningoceles CSF fistulas, whereas the bilateral approach is indicated for benign and malignant tumors of the anterior skull base meningioma except sellar tubercle(2-3-6-7). The bilateral approach is used for the olfactory meningioma, the Esthesioneuroblastoma, squamous cell carcinoma and juvenile angiofibroma, but the decision of the medial or lateral approach compared to the middle turbinate depends on the location of the lesion, its size and its lateral extension. Resection of the middle turbinate, for some authors is mandatory and bilateral regardless of the tumor volume, for others, and especially in case of small olfactory meningioma, a transnasal trans-cribriform approach with preservation of one or both middle turbinets is required, a wide opening of the ethmoidal sinus is performed for adequate exposure.

\section{1-Indications :}


1-1-The olfactory meningioma and the meningo-encephalocoele are benign lesions which represent an indication of choice for thisapproach (14).This approach provides direct access to the basal dural insertion of the meningioma, vascularized by the ethmoid arteries, and is usually bilateral. In addition, this approach provides an opportunity not only for removal of the tumor but also the dura and bone invaded by the lesion.

1-2-the fronto- ethmoid meningo- encephalocele and meningocele: lesions are common in this region, whether spontaneous or post- traumatic origin.

1-3-Osteo-dural defectat the anterior skull basespontaneous or traumatic origin, it is clinically manifested by rhinorrhea with recurrent meningitis

1-4- Othermalignant tumours like;Esthesioneuroblastoma, juvenile angiofibroma and squamous cell carcinoma which originates from the sinus, while Esthesioneuroblastoma or olfactory neuroblastoma arisefrom the olfactory epithelium (2-3-9-10-13). Although these tumors are often unilateral, but spread quickly through the cribriform plate into the anterior cranial fossa and contralateral sinus. The patient usually presents with nasal obstruction and epistaxis. The role of endonasal endoscopic approach in the treatment of these tumors has evolved; may be combined with a transcranial approach in order to achieve total resection followed by radiation therapy.

2-The contra-indications:Tumors with a significant lateral extension may be preferred for transcranial resection because the distance between the internal wall of the orbit and the crista Galli is $22+/-04 \mathrm{~mm}$ (6). The decision to address a malignant tumor by this minimally invasive approach must involve a team including: the oncologist, neurosurgeon and ENT, this decision varies from team to team.

3-Morbidity-mortality:The recent introduction of transnasal endoscopic surgery in the pituitary surgery and was extended to surgery of tumors of the anterior cranial fossa, helped to significantly reduce mortality and postoperative morbidity related to surgery of olfactory meningiomas. Any time according to different small series in the literature, the potential role of endoscopic resection of meningiomas of the anterior floor of the skull base in particular olfactory meningiomas is not well defined and that no critical evaluation date in the literature about its effectiveness has been established.

The series with significant decline is limited, typically the authors stress the surgical technique and results but never focused their work on the long-term monitoring. Most series have a tracking 06-24mois (1-2-36-7-9-12).

However no conclusions were issued in relation to the effectiveness of this therapeutic strategy. The most common complication of endoscopic approach to skull base meningiomas especially olfactory is CSF fistula. The high rate of the fistula is explained by the width of osteo- dural defect that goes from the posterior wall of the frontal sinus in the sphenoid planum. The rate of CSF fistula is 32\% ranging from 0-40 \% depending on the experiments (1). Gardner et al reported 04 cases of CSF fistula (26.7\%) of 15 patients (1-12). Diviitis et al report a fistula $(25 \%)$ of 04 cases treated by endoscopic approach.

4-The extent of resection:most of the authors agree that the quality of tumour resection is similar in both endoscopic and transcranial approaches (total resection was $86.4 \%$ for the trans- nasal endoscopic surgery against $83.3 \%$ for the conventional surgery).All times resection is reported as total in the series of endoscopic surgery but not graded according to the Simpson system making comparison difficult (12-16-17-18). Gardner et al report in a recent series total and subtotal resection in $83 \%$ (10 out of 12 cases olfactory meningiomas) with a CSF fistula rate of $2.7 \%$. From Diviitis et al report a total resection in 04 patients $(100 \%)$ with a CSF fistula rate in a single patient (25\%) (1-7). Table No. 02

Diviitis et al (8) reported a complete resection in 06 patients out of 07 (4,5).Jamie et al reported an analysis on a retrospective study of literature; 69 anterior cranial fossa meningiomas of which 50were sellar tubercle meningiomas, total resection in $76 \%$ of cases and subtotal resection in $12 \%$ of cases, CSF fistula in $34 \%$ of cases (17). Table 02 summarizes the resultsof sellar tubercle meningiomas surgery in some recent series in the literature Table No. 03:

Esthesioneuroblastoma:In a series published by Gallia et al in 2011 on 08cases operated between 2005 and 2010, including 06 cases of primary tumors and two cases of recurrence (11). The number of patients according to Kadish; A: one case (12.5\%), B: two cases ( $25 \%)$ C: 04 cases $(50 \%)$, D: one case $(12.5 \%)$. The complete tumor resection in 06 patients $(89.4 \%)$. No postoperative complications, survival is 27 months.

Some authors find that the rate of survival at 5 years increases from 10 to $15 \%$ when surgery is associated with the radiotherapy (20). The 5-year survival rates for irradiated patients is about $23 \%$. It increases to $44 \%$ when radiotherapy is associated with surgery (20).

5-Tumor recurrence: olfactory meningioma extending into the nasal cavity and the ethmoidal sinus was seenin $15 \%$ of the total cases; Simpson I resection including the dural attachment and bone infiltrated by tumor and hyperostosis at the base of the skull (the cribriform plate) is essential to prevent tumor recurrence.But many surgeons prefer a more conservative approach with Simpson II resection without resection of the hyperostosis of the cribriform plate, avoiding getting into the paranasal sinuses because of the risk of postoperative CSF fistula. 
The olfactory meningioma recurrence rate is significant; $30 \%$ at 05 yearsto $41 \%$ at 10 years of the incomplete tumor excision.Ethmoid sinus and cribriform plate are the most common sites of recurrence with extension into the paranasal sinuses and nasal cavity. The rate of hyperostosis at the base of the skull was $86 \%$, Deromeand Giout reported $15 \%$ of the olfactory meningiomas which extended into the paranasal sinuses. Spektor et al on a series of 81 patients reported $26.3 \%$ with invasion of the paranasal sinuses (1).In the series of Al mefty every patient who relapsed an olfactory meningioma had hyperostosis at the base of the skull (1).

The advantage of the endoscopic approach is the removal of the tumor in the nasal cavity first then in the paranasal sinuses, excision of the hyperostosis by resection of the cribriform plate and also the excision the dural attachment which allows a complete Simpson I resection to prevent recurrence (15-16-17-18-19).

-theosteo- dural defect:The osteo- dural defect at the cribriform plate of the ethmoid represent 54, 5\% of the skull base lesions in our series. Their clinical diagnosis was based on the presence of a leakage of CSF (rhinorrhea) with recurrent meningitis, this symptom was present in all patients (100\%) contrary to the literaturewhere rhinorrhea was $(64 \%)$, meningitis $(10 \%)$ and headache in $(08 \%)$. The most common cause of this defectis traumatic in 55\% of cases with only one case of iatrogenic origin, corresponding to the figures of the literature (5-21). CT scan coronal and sagittal slices was our examination of choice to determine the exact location of thedefect, brain MRI is rarely requested on contrast isotope transit is systematic (100\%). In our series the most frequent location is the cribriform plate of the ethmoid for posttraumatic CSF fistula while their frequencies vary from one series to another in the literature.

Endoscopic repair is the treatment of choice, the surgical approach is based on the location of the CSF leakage at the base of the skull. As in our series the most frequent location is the cribriform plate of the ethmoid bone, we used the endoscopic endonasal trans ethmoidal trans-cribriform approach in all patients with a single trans- ethmoidal approach to an iatrogenic leakage. In the series published by David Locatelli et al, he used the endoscopic trans cribriform approach in 50\% of cases and trans- ethmoid approach in 35\% of cases (5).Using fluorescein intraoperatively to identify and locate the site of the fistula was reported in the literature in several publications, in our series we never used fluorescein. We have used the multilayers technique described by Kassem et al for the repair of osteo- dural defect and the underlay techniquedepending on the location of the defect at the cribriform plate of the ethmoid.

In the literature, all of the authors use fibrin glue with a balloon stent to keep the repair device in place, but in our work we used a Folley catheter balloon (balloon of a urinary catheter).For closing the defect, we used fascia lata, medium turbinate mucosa, the bone of the middle turbinate, the septal cartilage, the bone of the perpendicular plate of the ethmoid, abdominal fat and synthetic dura matter like most authors.

Other authors sutured the osteodural defect with U-clips used for cardiovascular anastomoses, temporal fascia, silasticsplints, Flosealand titanium to close the bone defect. We had to use the nasal septal pedicle flap of Hadad in $100 \%$ of cases. Overall morbidity reported in the literature is negligible in most series outside rhinologic complications like synechia and crust(5-21). In our series we observed the same complications, namely synechia and crusts. Our results were satisfactory, of the 54 cases we had four postoperative recurrences after a period ranging from 06 months - 1 year.Revision surgery bytrans cranial approach was done in a young unruly patient who had ameningoencphalocoele, while in the literature there're several authors reporting cases of revision surgery by a trans cranial approach. Two patients were reoperated endoscopically with a $100 \%$ success.In literature the success rate of the endoscopic procedure is $83-95 \%$ for the first intervention and 86$100 \%$ during the reoperation vis-à-vis a failure rate of $10-40 \%$.In our series the success rate is $92.8 \%$ of cases.

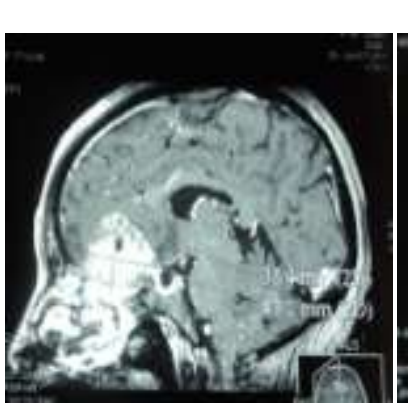

Figures and Tables

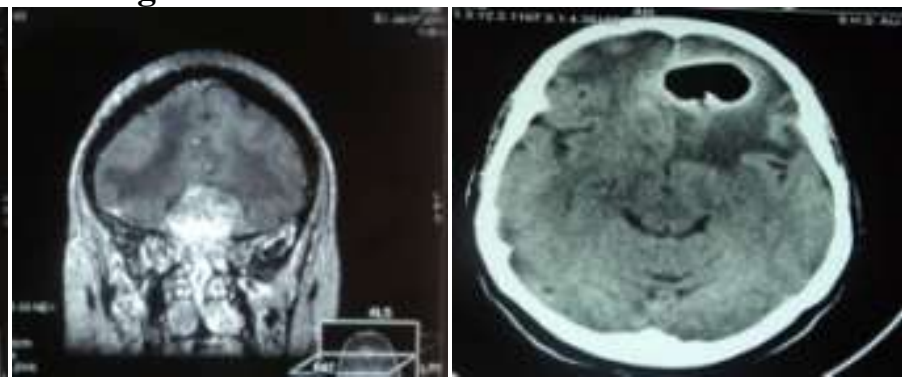



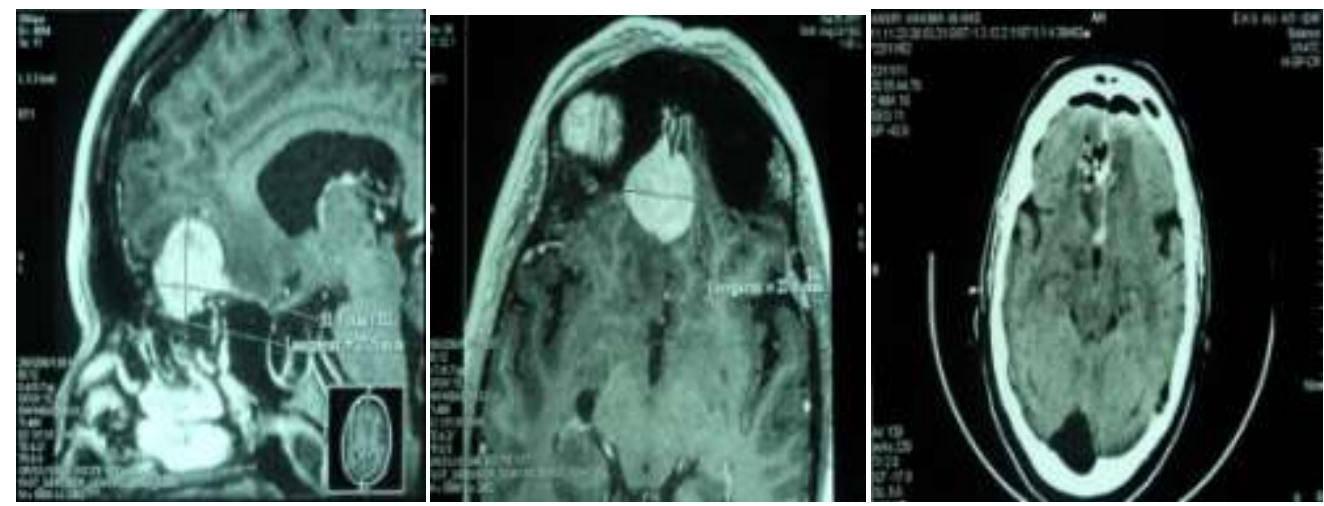

Fig1: -Preoperative sagittal and frontal MRI cuts shows the olfactory meningioma with invasion of the cribriform plate and the posterior ethmoid bone.

-the postoperative CT scan that shows the quality of resection.

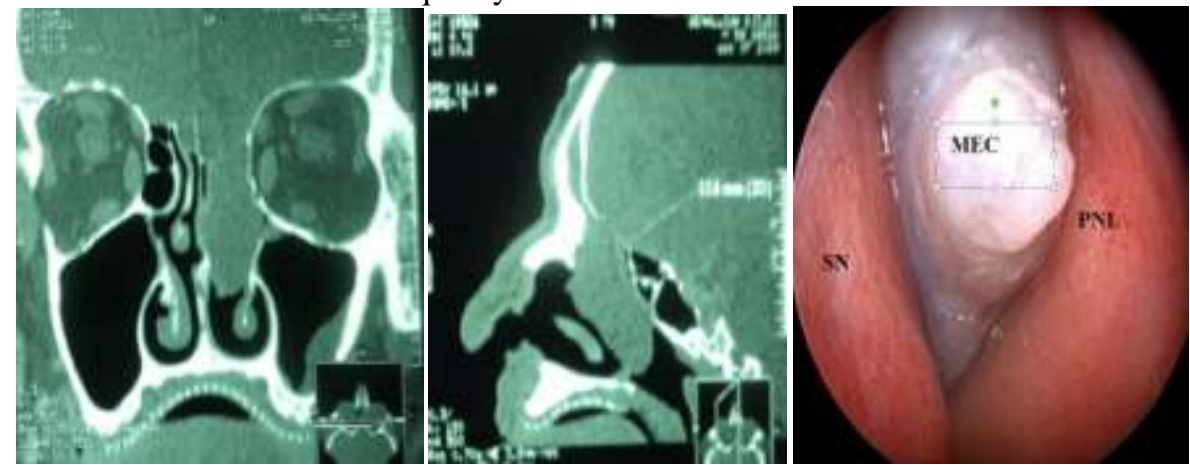

Fig2:-Preoperative CT scan coronal and sagittal sections shows a left fronto- ethmoid meningo- encephalocoele. Endoscopic -view a left fronto- ethmoid meningo- encephalocoele.

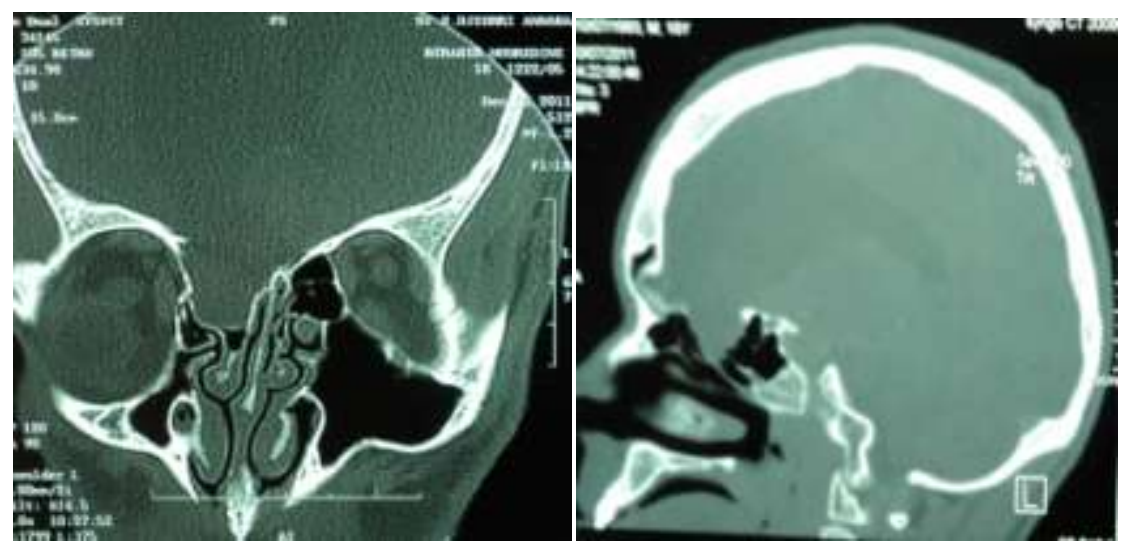

Fig3:-Preoperative CT scan coronal and sagittal sections shows a rightfronto- ethmoidmeningo- encephalocoele.
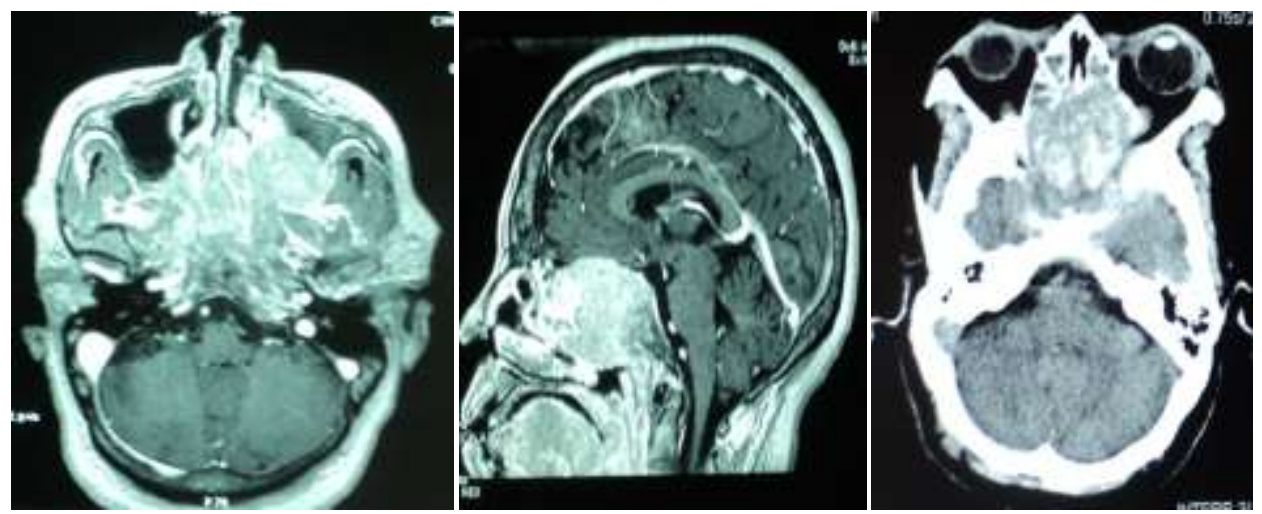


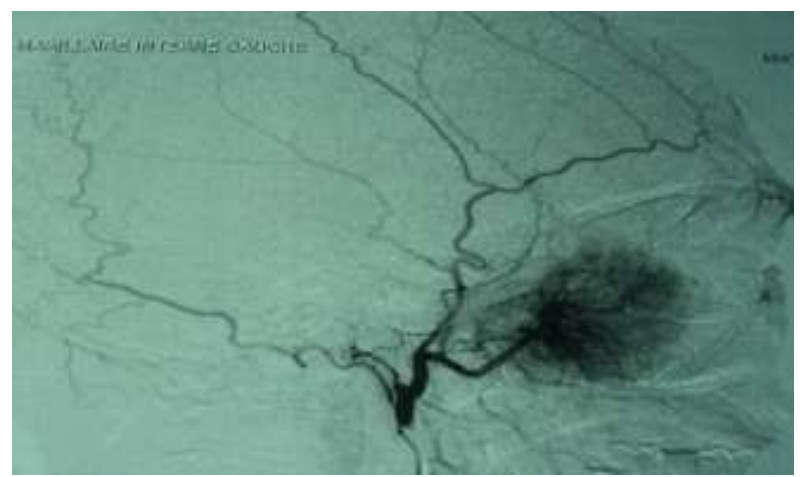

Fig4:-Preoperative scanner and MRI; sagittal and axial sections show an ethmoidal carcinoma with arteriography showing that it is a vascularized tumor.
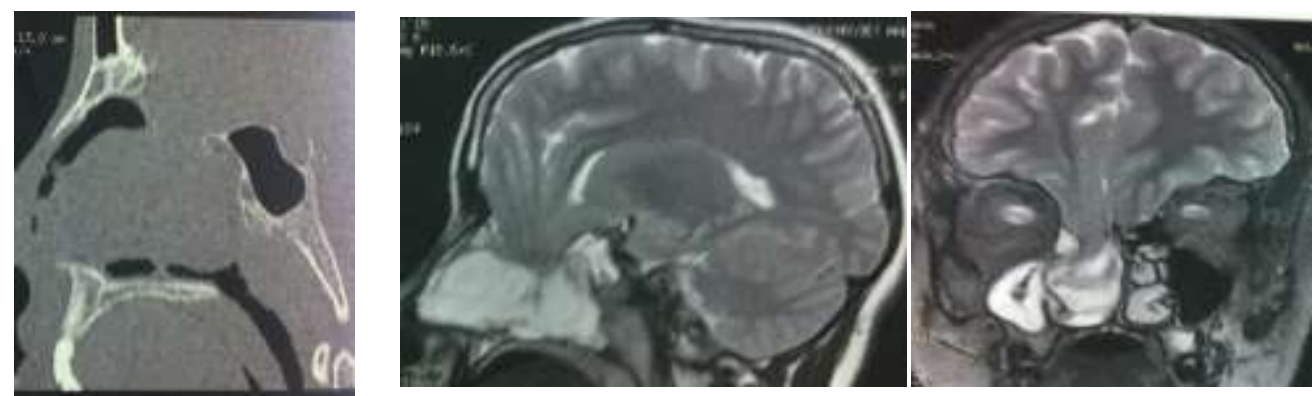

Fig5: - Preoperative CT and MRI in sagittal and frontal sections show a right fronto- ethmoid meningoencephalocoele

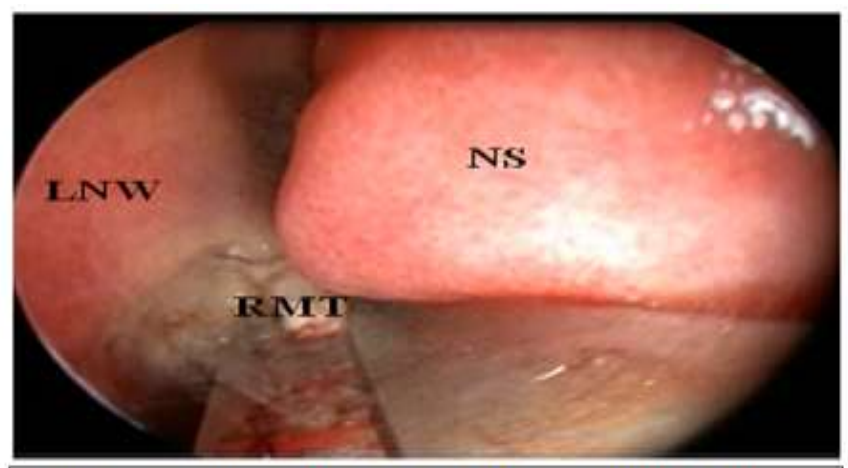

Fig2 : an endoscopic view of the resection of the right middle turbinate.

LNW: lateral nasal wall, RMT: right middle turbinet, SN : nasal septum.

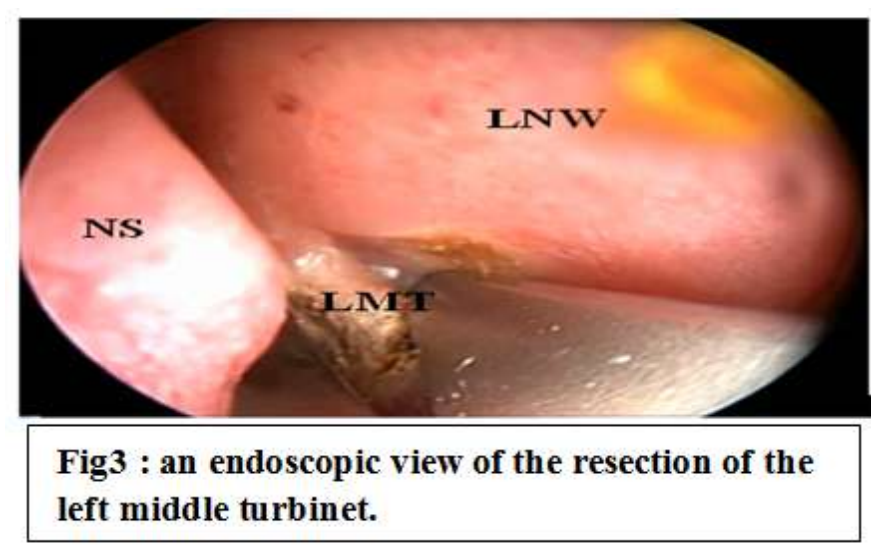

LNW: lateral nasal wall, LMT: left middle turbinet, NS: nasalseptum. maxillary sinus(fig 4). 


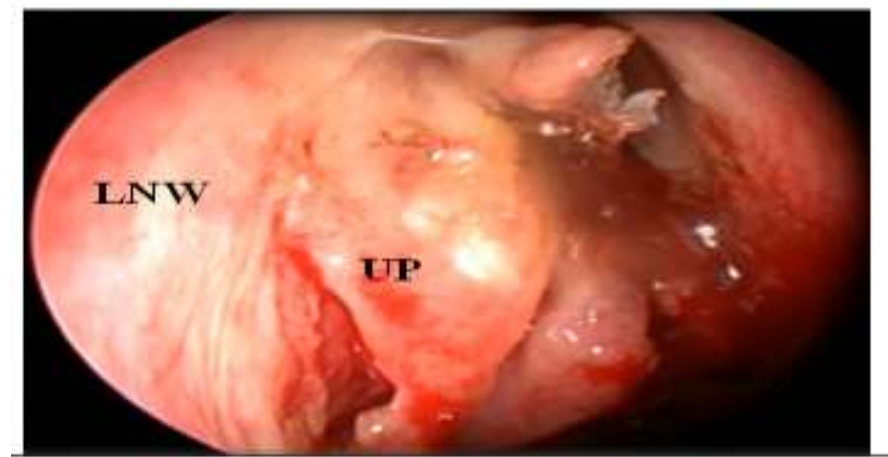

Fig 4: an endoscopic view of the incision and the resection of the uncinate process.

LNW: lateral nasal wall, UP : uncinateprocess.

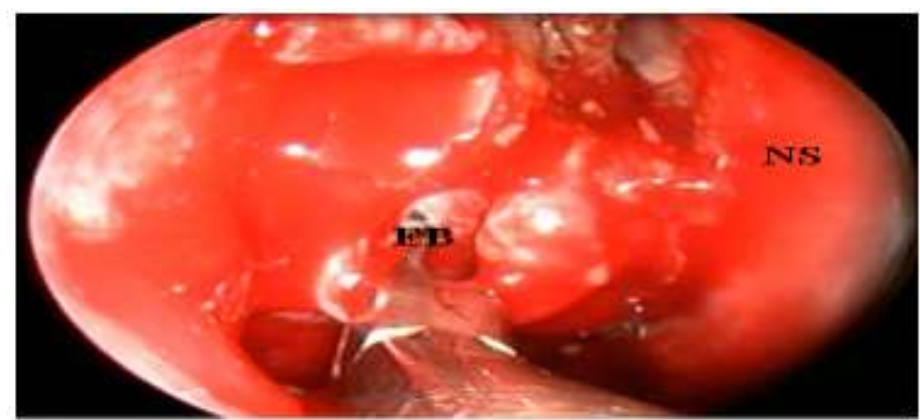

Figs: endoscopic view or the resection or the ethmoidal bulla

EB: ethmoidalbulla, NS: nasalseptum

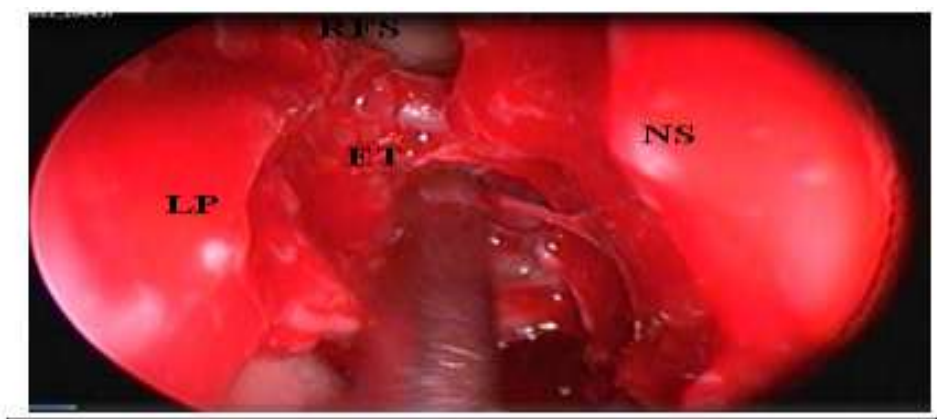

Fig6: endoscopic view of the frontal recess and acomplete right ethmoidectomy

RFS : right frontalsinus, LP : lamina papyracea, NS : nasal septum, ET : ethmoidectomy.

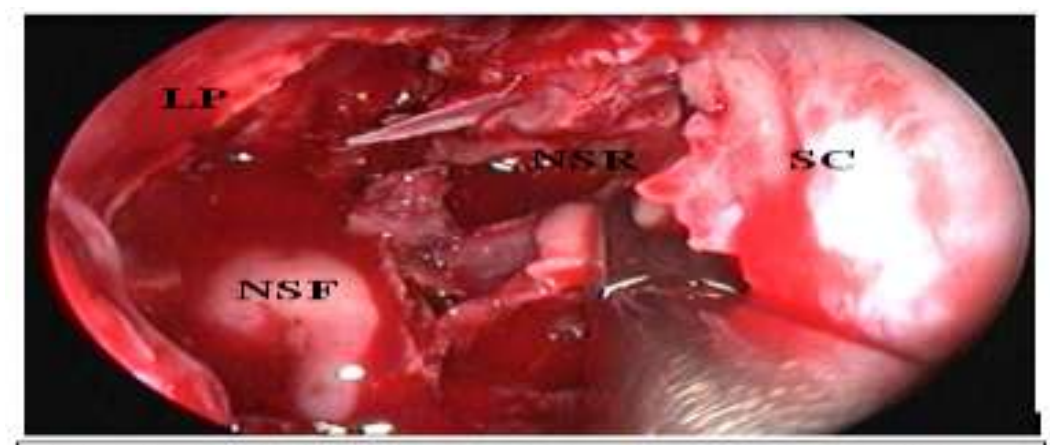

Fig 7 : endoscopic viev of the resection of nasalseptum giving a bilateral access.

SC : septalcartilage, LP : lamina papyracee, NSR : nasalseptumresection, NSF :naso-septalflap 


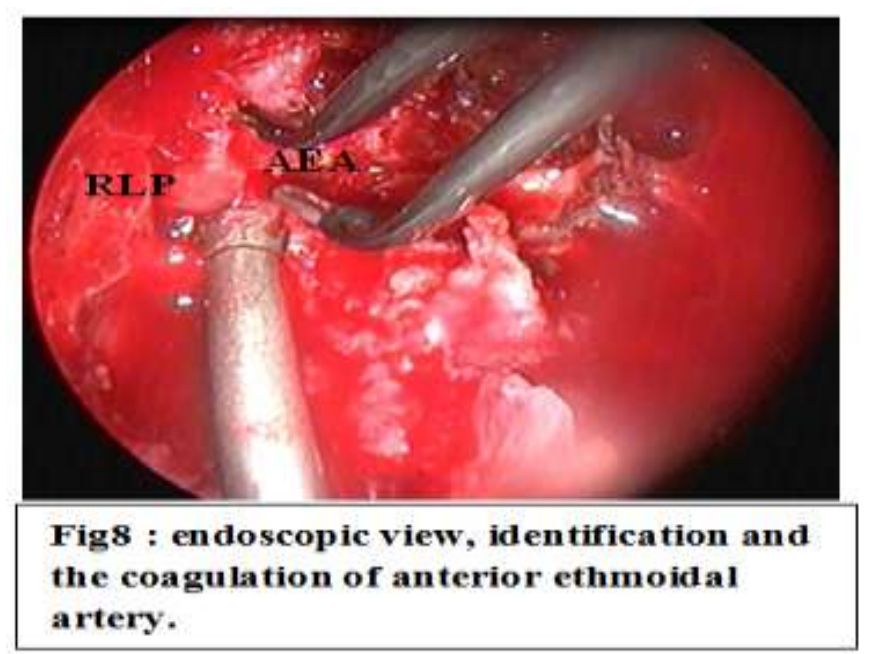

RLP : right lamina papyracee, AEA : anteriorethmoidal artery.

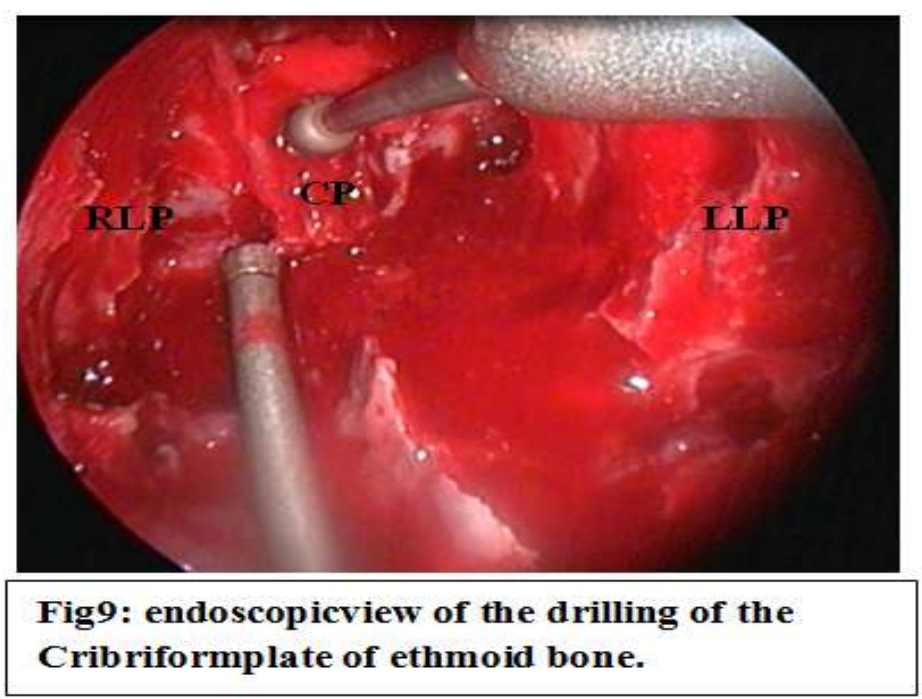

RLP: right lamina papyraceaLLP :left lamina papyracea, CP: the cribriform plate.

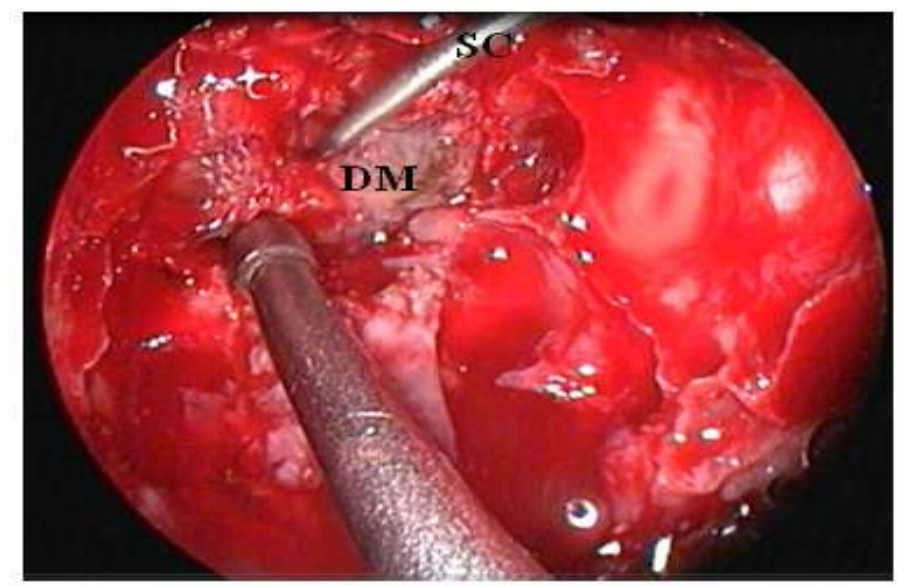

Fig10 : endoscopicview of the opening of the dura mater

DM : dura mater, SC : scalpel. 


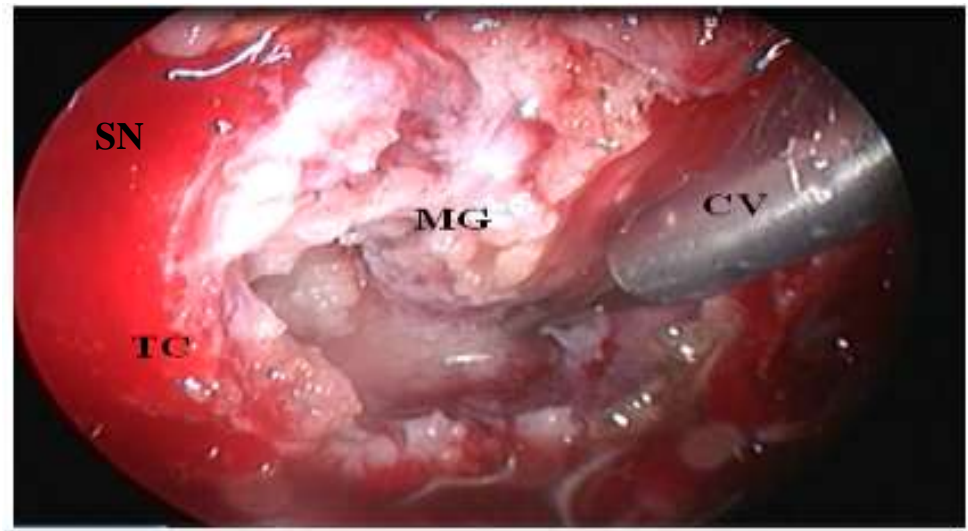

Fig 11: endoscopic view of tumoral resection by cavitron ultrasonic surgical aspirator

TC: tumor capsule, MG: meningioma, TR: tumor recess CV: the CUSA

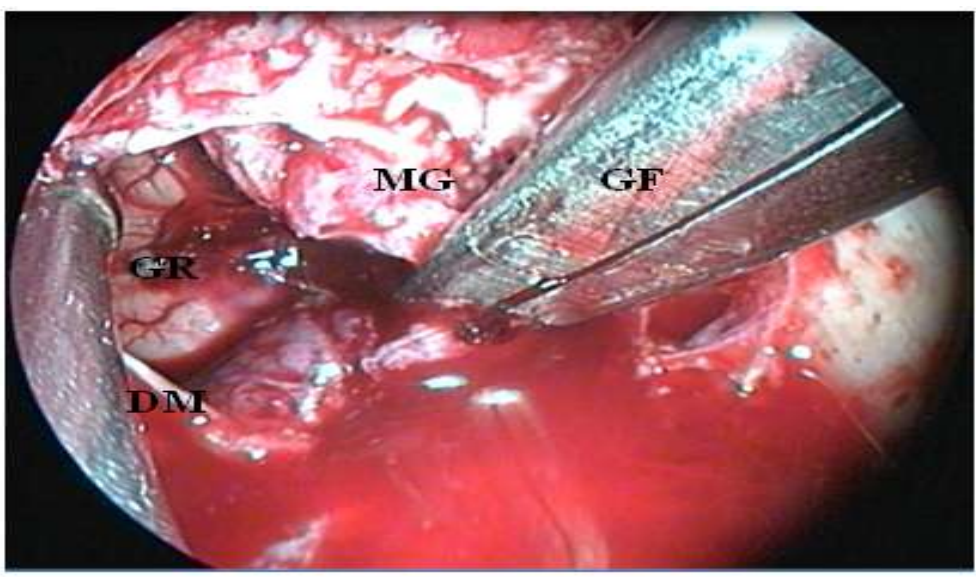

Fig 12 : endoscopic view of the extra capsular dissection

MG: meningioma, GR: the inferior surface of the gyrus rectus, DM: healthy dura mater GF: grasping forceps.

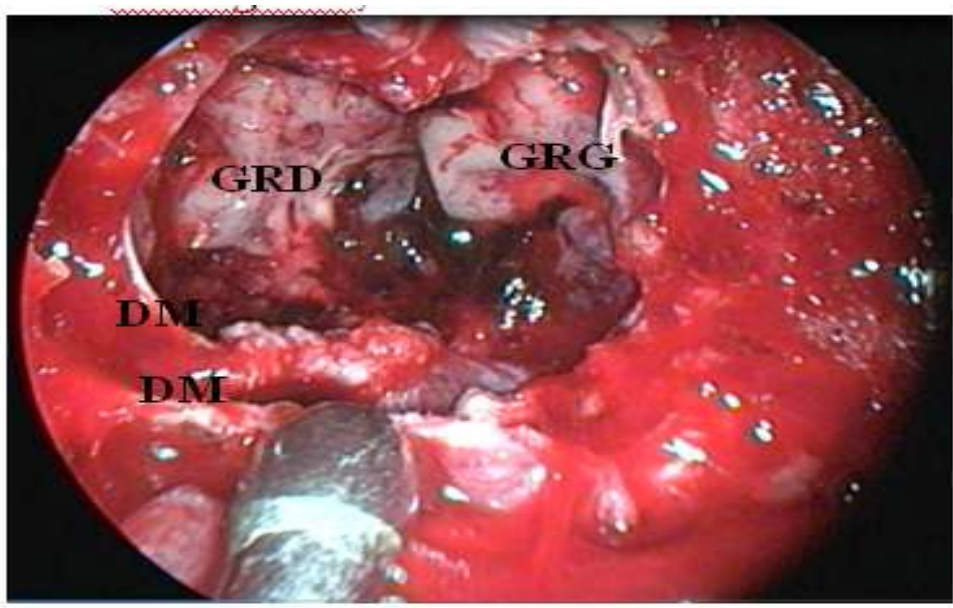

Fig 13 : endoscopic view of the gyrus rectus after complete excision of a meningioma

RGR : right gyrus rectus, LGR : leftgyrus rectus, DM : dura mater 


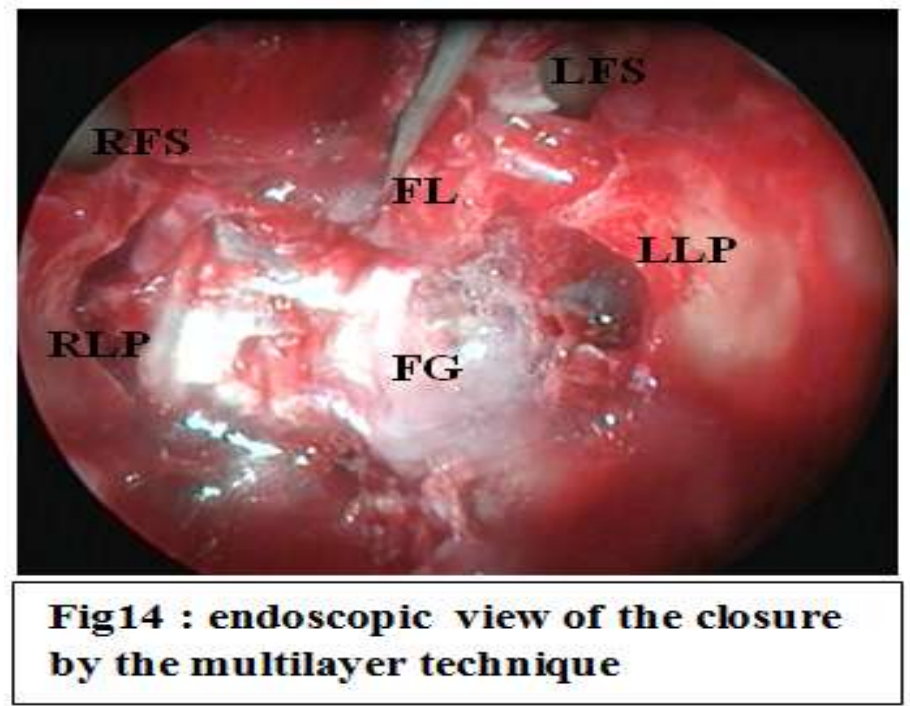

RFS :right frontal sinus, LFS :left frontal sinus, FL : fascia lata, FG : fibrin glue, RLP : right lamina papyracée,

\begin{tabular}{|l|c|c|}
\hline The tumour & Number & Extent of resection $(\%)$ \\
\hline Olfactory Mg & 05 & Total : $100 \%$ \\
\hline Mg of sellartubercle & 02 & Total : $100 \%$ \\
\hline EthmoidalAdenocarcinoma & 04 & Subtotal : $100 \%$ \\
\hline Récidive d'un méningiome du toit de l'orbite & 01 & Total \\
\hline Naso-pharyngealFibroma & 01 & Total \\
\hline Esthesioneuroblastoma & 04 & Partial \\
\hline Ethmoid-orbital Osteoma & 01 & Subtotal \\
\hline
\end{tabular}

LLP : left lamina papyracée

Table No.01: Extent of surgical resection in the tumours of the anterior skull base

\begin{tabular}{|l|l|l|l|l|l|}
\hline authors & Number & $\begin{array}{l}\text { Olfactory } \\
\text { meningioma }\end{array}$ & $\begin{array}{l}\text { Sellar tubercle } \\
\text { meningioma }\end{array}$ & year & CSF Fistula \\
\hline $\begin{array}{l}\text { Fatemi et al., } \\
\mathbf{2 0 0 9}\end{array}$ & 14 cases & 00 & 14 & $\begin{array}{l}2000- \\
2008\end{array}$ & $29 \%(4$ cases $)$ \\
\hline Wang et al. 2009 & 07 & 00 & 07 & $\begin{array}{l}2002- \\
2007\end{array}$ & $14 \%(01$ cases $)$ \\
\hline $\begin{array}{l}\text { Gardner et al., } \\
\text { 2008 }\end{array}$ & 28 & 15 & 13 & $\begin{array}{l}2002- \\
2005\end{array}$ & $43 \%(12$ cases $)$ \\
\hline $\begin{array}{l}\text { de Divitis et al. } \\
\mathbf{2 0 0 8}\end{array}$ & 11 & 04 & 07 & $2004-$ & $27 \%(03$ cases $)$ \\
\hline $\begin{array}{l}\text { Dehdashti et al. } \\
\text { 2009 }\end{array}$ & 01 & 01 & 01 & - & $100 \%$ \\
\hline Cook et al.2004 & 03 & 00 & 03 & - & 00 \\
\hline $\begin{array}{l}\text { Laufer et al., } \\
\text { 2007 }\end{array}$ & 05 & 00 & 05 & - & $20 \%(01$ case $)$ \\
\hline $\begin{array}{l}\text { Jamie et al 2011 } \\
\text { Our series }\end{array}$ & 13 & 00 & 13 & $2003-$ & 00 \\
\hline & 07 & 03 & $2009-$ & 2 cases \\
\hline
\end{tabular}

Table No. 02: The different series of meningiomas of the anterior skull base operated by a transnasal endoscopic approach cited by Jamie.

\begin{tabular}{|c|c|c|c|c|c|}
\hline $\begin{array}{l}\text { Authors and } \\
\text { year }\end{array}$ & $\begin{array}{l}\text { Number of } \\
\text { cases }\end{array}$ & $\begin{array}{l}\text { Quality of } \\
\text { resection }\end{array}$ & Morbidity & Visual prognosis & Mortality \\
\hline $\begin{array}{ll}\text { De } & \text { divittis } \\
2007 & \end{array}$ & 06cases & $\begin{array}{l}\text { TR : } 83,3 \% \\
\text { STR : } 16,7\end{array}$ & $\begin{array}{l}\text { CSF } \\
\text { Fistula/16,7\% } \\
\text { DIP : } 16,7\end{array}$ & $\begin{array}{l}\text { Improvement: } \\
83,3 \% \\
\text { Aggravation : } 16,7 \%\end{array}$ & $16,7 \%(01$ case $)$ \\
\hline $\begin{array}{l}\text { Laufer et al } \\
2007\end{array}$ & 05cases & TR : $100 \%$ & $\begin{array}{l}\text { CSF Fistula: } \\
20 \% \\
\text { DI : } 20 \%\end{array}$ & $\begin{array}{l}\text { Improvement : } \\
100 \%\end{array}$ & - \\
\hline $\begin{array}{l}\text { Wang et al } \\
2010\end{array}$ & 12cases & $\begin{array}{l}\text { TR : } 91,6 \% \\
\text { STR : } 8,4 \%\end{array}$ & 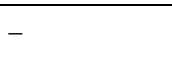 & $\begin{array}{l}\text { Improvement : } 92 \% \\
\text { Unchanged : } 8 \%\end{array}$ & - \\
\hline $\begin{array}{l}\text { James et al } \\
2011\end{array}$ & 13cases & $\begin{array}{l}\text { TR : } 53,84 \% \\
\text { STR: } 46,15 \%\end{array}$ & & $\begin{array}{l}\text { Improvement: } \\
38,46 \% \\
\text { Stable : } 30,76 \%\end{array}$ & $\begin{array}{l}7,69 \% \\
(01 \text { case })\end{array}$ \\
\hline
\end{tabular}


The Role Of Endoscopy In The Surgery Of Cerebrospinal Rhinorrhea In Children.

\begin{tabular}{|l|l|l|l|l|l|}
\hline & & & & \\
\hline \begin{tabular}{ll|l} 
Our series \\
2015
\end{tabular} & 03 & TR : 100\% & $\begin{array}{l}\text { CSF } \\
\text { Fistula : } \\
\text { 33\% } \\
\text { DI : 33\% }\end{array}$ & $\mathbf{1 0 0 \%}$ & \multirow{2}{*}{0} \\
\hline
\end{tabular}

Table No. 03: The results of different series of meningiomas of the sellar tubercle operated by an endoscopic trans- planumapproach .

\section{Conclusion}

The endoscopic endonasal surgery has taken an undeniable place in the treatment oflesions of the anterior skull base.It is a minimally invasive surgery with less morbidity compared to the intracranial approaches and should be the current practice.

\section{References}

[1]. Amin B. Kassam, M.D.,1,2 Daniel M. Prevedello, M.D.,1 Ricardo L. Carrau, M.D.,1,2Carl H. Snyderman, M.D.,1,2 Ajith Thomas, M.D.,1 Paul Gardner, M.D.,1Adam Zanation, M.D.,2 Bulent Duz, M.D.,3 S. Tonya Stefko, M.D.,1,4 Karin Byers, M.D.,5 and Michael B. Horowitz, M.D.1 :Endoscopic endonasal skull base surgery: analysis of complications in the authors' initial 800 patients A review.J Neurosurg 114: 2011.1544-1568.

[2]. Castelnuovo P, Bignami M, Delù G, Battaglia P, Bignardi M, Dallan I :Endonasal endoscopic resection and radiotherapy in olfactory neuroblastoma: our experience.Head Neck. 2007 Sep; 29(9):845-50.

[3]. Ceylan S, Koc K, Anik I: Extended endoscopic approaches for midline skull-base lesions. Neurosurg Rev. 2009 Jul; 32(3):30919.

[4]. Darlene Lubbe, Patrick Semple, Johan Fagan: Advances in endoscopic sinonasal and anterior skull base surgery. August 2008, Vol. 98, No. 8 SAMJ

[5]. Davide locatelli, M.D. federicorampa, M.D. ilariaacchiardi, M.D. Francesca de bernardi, M.D. paolocastelnuovo, m.d: endoscopic endonasal approaches for repair of cerebrospinal fluid leaks: nine-year experience. Jns-246 | volume 58 | operative neurosurgery $2 \mid$ April 2006.

[6]. Dehdashti AR, Ganna A, Witterick I, Gentili F: Expanded endoscopic endonasal approach for anterior cranial base and suprasellar lesions: indications and limitations.Neurosurgery. 2009 Apr; 64(4):677-87.

[7]. Enrico de Divitiis, FeliceEsposito, Paolo Cappabianca, Luigi Maria Cavallo,oreste de Diviitis and Isabella esposito: Endoscopic Endonasal resection of anterior cranial fossa meningiomas .Neurosurgery focus/volume25/decembre 2008.

[8]. Enrico de Divitiis, Felice Esposito, Paolo Cappabianca, Luigi Maria Cavallo, oreste de Diviitis: Endoscopic Endonasal resection of midline cranial base tumors. JBNC19 (2):7-17, 2008

[9]. Fernandez-Miranda JC, Gardner PA, Prevedello DM, Kassam A: Expanded endonasal approach for olfactory groove meningioma.ActaNeurochir (Wien). 2009 Mar; 151(3):287-8.

[10]. Folbe A, Herzallah I, Duvvuri U, Bublik M, Sargi Z, Snyderman CH, Carrau R, Casiano R, Kassam AB, Morcos JJ :Endoscopic endonasal resection of esthesioneuroblastoma: a multicenter study. Am J Rhinol Allergy. 2009 Jan-Feb; 23(1):91-4.

[11]. Gallia GL, Reh DD, Salmasi V, Blitz AM, Koch W, Ishii M :Endonasal endoscopic resection of esthesioneuroblastoma: the Johns Hopkins Hospital experience and review of the literature.Neurosurg Rev. 2011 Jun 8.

[12]. Gardner PA, Kassam AB, Thomas A, Snyderman CH, Carrau RL, Mintz AH, Prevedello DM :Endoscopic endonasal resection of anterior cranial base meningiomas..Neurosurgery. $2008 \mathrm{Jul}$; 63(1):36-52; discussion 52-4.

[13]. Greenfield JP, Anand VK, Kacker A, Seibert MJ, Singh A, Brown SM, Schwartz TH: Endoscopic endonasaltransethmoidaltranscribriformtransfoveaethmoidalis approach to the anterior cranial fossa and skull base..Neurosurgery. 2010 May; 66(5):883-92.

[14]. Gurston G. Nyquist, M.D., 1 Vijay K. Anand, M.D., 1 SaralMehra, M.D., M.B.A., 1AshutoshKacker, M.D., 1 and Theodore H. Schwartz, M.D. 1, 2: Endoscopic endonasal repair of anterior skull base non-traumatic cerebrospinal fluid leaks, meningoceles, and encephalocelesJNeurosurg.2010.113:961-966.

[15]. hilal a. kanaan, m.d.1 paul a. gardner, m.d.,1 gabrielleyeaney, m.d.,2 daniel m. prevedello, m.d.1 edward a. monaco iii, m.d., ph.d.,1 geoffreymurdoch, m.d.,2 ian f. pollack, m.d.,1 and amin b. kassam, m.d.1 :expanded endoscopic endonasal resection of an olfactory schwannoma case report.Jneurosurg pediatrics 2008.2:261-265.

[16]. James K. Liu, M.D.,1,2 Lana D. Christiano, M.D.,1 Smruti K. Patel, B.A.,1 R. Shane Tubbs, M.S., P.A.-C., Ph.D.,3 andJean Anderson Eloy, M.D.2 :Surgical nuances for removal of olfactory groove meningiomas using the endoscopic endonasaltranscribriform approach.Neurosurg Focus 30 (5):2011. E3.

[17]. Jamie J. Van Gompel, M.D.,1 Giorgio Frank, M.D.,2 Ernesto Pasquini, M.D.,2Matteo Zoli, M.D.,2 Jason Hoover, M.D.,1 and Giuseppe Lanzino, M.D.1 :Expanded endonasal endoscopic resection of anterior fossa meningiomas: report of 13 cases and meta-analysis of the literature.Neurosurg Focus 30 .2011.(5):E15,

[18]. Jho HD, Ha HG:Endoscopic endonasal skull base surgery: Part 1--The midline anterior fossa skull base. Minim Invasive Neurosurg. 2004 Feb; 47(1):16-23.

[19]. Kalinin PL, Fomichev DV, Kutin MA, Kadashev BA, FaĭzullaevRB.ZhVoprNeirokhirIm N NBurdenko: Extended endoscopic endonasaltranssphenoidal approaches in skull base surgery. 2008 Oct-Dec ;(4):47-9; Russian.

[20]. Parsons JT, Mendenhall WM, Mancuso AA, et al: Malignant tumors of the nasal cavity and ethmoid and sphenoid sinuses.Int J RadiatOncBiol Phys 14:1-22, 1988

[21]. Schmerber S, Righini C, Lavielle JP, Passagia JG, Reyt E :Endonasal endoscopic closure of cerebrospinal fluid rhinorrhea.Skull Base. $2001 \mathrm{Feb}$; 11(1):47-58. 